\title{
Effect of fatty acid composition of methyl and ethyl esters on the lubricity at different humidities
}

\author{
Magín Lapuerta $^{\mathrm{a}, *}$, Jesús Sánchez-Valdepeñas ${ }^{\mathrm{a}}$, David Bolonio ${ }^{\mathrm{b}}$, Ekarong Sukjit ${ }^{\mathrm{c}}$ \\ ${ }^{a}$ University of Castilla La-Mancha, Escuela Técnica Superior de Ingenieros Industriales, Avda. Camilo José Cela s/n, 13071 Ciudad Real, Spain \\ ${ }^{\mathrm{b}}$ Universidad Politêcnica de Madrid, Department of Energy ó Fuels, ETS Ingenieros de Minas y Energía, Ríos Rosas 21, 28003 Madrid, Spain \\ ${ }^{\mathrm{C}}$ Suranaree University of Technology, School of Mechanical Engineering, Institute of Engineering, 111 University Avenue, Nakhon Ratchasima 30000, Thailand
}

\begin{abstract}
A B S T R A C T
Lubricity of individual fatty acid methyl or ethyl esters and biodiesel fuels has been measured using a high frequency reciprocating rig (HFRR). Tests have been carried out varying the ambient humidity to assess the effect of this parameter on the lubricity of the fuels. The European standard proposes a single humidity correction factor for all the fuels, regardless their composition. It has been proved in this study that this factor is not constant and it depends on the fuel composition. For this reason two different correlations have been proposed for the estimation of the humidity correction factor and normalized wear scar as a function of different fuel compositional characteristics. The influence of the water content on the lubricity and the relationship between humidity and water content of the fuel has been studied revealing that the effect of the air humidity is an indirect effect of the hygroscopy of the fuel.
\end{abstract}

\section{Introduction}

The improvement of common-rail systems in diesel engines has allowed the transport companies to develop new strategies to increase engine efficiency and reduce pollutant emissions. One of the strategies developed by the manufacturers is to use higher injection pressures to atomize the fuel, leading to better air mixing, faster evaporation and more efficient combustion process. Severely-loaded systems such as injectors or pressure pumps need fuels with high lubricating capacity to avoid any wear problem. However, almost all of the petroleum-based diesel fuels available in Europe and North America are now of ultra-low sulfur diesel (ULSD) type, to accomplish with the new environmental policies about limiting sulfur. The low sulfur diesel fuel has poor lubricity, caused by the removal of polar oxygen and nitrogen compounds,

\footnotetext{
* Corresponding author.

E-mail address: Magin.Lapuerta@uclm.es (M. Lapuerta)
}

which happens during the process of sulfur species extraction. These polar compounds are adsorbed on the rubbed metal surfaces providing a protective layer that reduces adhesion and limit friction or wear [1].

To restore the lubricity of these fuels, the use of additives or blends with another fuel of enhanced lubricity is required [2]. For this reason the influence of different compounds on the lubricity of diesel fuels has been tested and oxygenated compounds were ordered regarding their lubricity enhancing potential $\left(\mathrm{COOH}>\mathrm{CHO}>\mathrm{OH}>\mathrm{COOCH}_{3}>\mathrm{C}=\mathrm{O}>\mathrm{C}-\mathrm{O}-\mathrm{C}\right)$ [3]. Biodiesel, an alternative diesel fuel derived from the transesterification of vegetable oils or animal fats, can be used in blends with diesel to improve the lubricity, because biodiesel contains polar oxygenated compounds. Moreover, biodiesel is an environment-friendly option that can be cheaper than other kind of additives. Biodiesel-diesel blends have been widely studied and it is well known that biodiesel reduces the particulate matter and $\mathrm{CO}$ emissions and increases cetane number and flash point of diesel in blends [4-6]. In 
addition, biodiesel may not require engine modifications when used in blends up to $20 \%(\mathrm{~m} / \mathrm{m})$ in diesel, as far as cold-flow properties are the required ones for the climate conditions [7]. Biodiesel can be produced with methanol or ethanol resulting in fatty acid methyl esters (FAMEs) or ethyl esters (FAEEs), respectively, both compounds having inherent good lubricity. Generally there are fewer studies of FAEEs because the lower price of methanol has made FAMEs to be widely used and also because the base catalyzed production of FAEEs is more difficult than the production of FAMEs. During the course of reaction, emulsions are usually formed, which in the case of methanolysis easily break down but, in ethanolysis are more stable, probably because of the formation of monoglycerides [8], and complicate the separation and purification of esters. Nevertheless, FAEEs have been industrially produced in places like Brazil and the development of new biotechnologies for the production of bioethanol can favor the use of ethanol, what would convert the biodiesel in a total renewable source of energy [9]. The amounts of biodiesel needed to improve the lubricity of the diesel fuel are low. In fact, previous studies show how the reduction of lubricity tends to stabilize at concentrations higher than $1 \%$ by volume [10]. It is also interesting the effect on lubricity of the impurities of biodiesel, as free fatty acids or monoacylglycerols. Both compounds, although present in minimum amounts ( $\approx 100 \mathrm{ppm}$ ), are major contributing factors to improve the lubricity of blends of biodiesel with diesel [11].

Lubricity is commonly measured through the high frequency reciprocating rig (HFRR) test due to the ability of providing a wide range of wear mechanisms [12]. It has been proved recently that the HFRR is also suitable for evaluating the wear performance of fuels in more severe contact conditions than those that may exist in future fuel injection equipment [13]. The test methods are specified in standards EN ISO 12156-1:2006 [14] and ASTM D 6079 [15] for Europe and US, respectively. In the US the ASTM D975 [16] limit is $520 \mu \mathrm{m}$, in Europe the EN 590 [17] limit is $460 \mu \mathrm{m}$, while the World Wide Fuel Charter recommends a maximum wear scar of $400 \mu \mathrm{m}$ for diesel fuels to be commercialized in markets with advanced or highly advanced requirements for emission control and fuel efficiency [18].

Previous studies have shown that the lubricating properties of the fuel, hence the size of the wear scar in the HFRR test, are influenced by the relative humidity in the air, especially when low load is applied and oxidative wear is predominant [19]. Because of this, the ISO standard proposes a correction of the measured wear scar depending on the vapor pressure, using the so-called humidity correction factor $(H C F)$ which is set to $60 \mu \mathrm{m} / \mathrm{kPa}$ for all the fuels, regardless of their composition. This unchanged factor has been proved to underestimate or overestimate lubricity when dealing with different kind of fuels [20] and depends on the fuel chemical composition.

This work continues a previous study on lubricity [20], in this case focusing on biodiesel fuels and components. HCFs and wear scars of FAMEs and FAEEs are measured to study the influence of the biodiesel composition on the lubricity, taking into account the water content in the fuel and the effect of hygroscopy on the change of lubricity at different ambient humidities.

\section{Fuels and experimental schedule}

The following fuels were tested with the HFRR at the laboratory of the Fuels and Engines Group of the University of Castilla-La Mancha (UCLM):

- Pure methyl esters: Methyl laurate, myristate and stearate were donated by the University of Birmingham (these compounds were purchased from Sigma-Aldrich). Methyl palmitate was purchased from Alfa Aesar. The main characteristics of pure methyl esters are shown in Table 1.

- Synthetic ethyl esters were manufactured from pure fatty acids at the Universidad Politécnica de Madrid (UPM). Fatty acids were purchased from Sigma Aldrich and were transformed into the fatty acid ethyl esters through an esterification process described in the literature [21]. The purity of the esters was tested following the EN 14103 method. A Hewlett-Packard 5890 series II gas chromatograph equipped with FID detector and split/splitless injector and an HP-Wax column $(30 \mathrm{~m} \times 0.32 \mathrm{~mm}$ i.d. $\times 0.15 \mu \mathrm{m}$ ) of polyethylene glycol was used for the analysis. Properties of these compounds are shown in Table 1 and results of the chromatographic analysis are shown in Table 2 .

- Biodiesel fuel (FAME) from palm oil produced and donated by Antioquia University, and fulfils EN 14214 . The fatty acid profile was analysed with gas chromatography as previously described and the results are provided in Table 3 .

- Biodiesel fuels (FAEEs) from different kind of oils were also produced at UPM following a transesterification method described in the literature [22]. The composition was tested through gas chromatography and the results are shown in Table 4.

Table 1

Main properties of the methyl and ethyl esters.

\begin{tabular}{|c|c|c|c|c|c|c|c|}
\hline Fuel & $\begin{array}{l}\text { Molecular } \\
\text { formula }\end{array}$ & $\begin{array}{l}\text { Carbon number } \\
\text { in the acid chain }\end{array}$ & $\begin{array}{l}\text { Average number } \\
\text { of double bonds }\end{array}$ & $\begin{array}{l}\text { Molecular weight } \\
(\mathrm{g} / \mathrm{mol})\end{array}$ & $\begin{array}{l}\text { Melting } \\
\text { point }\left({ }^{\circ} \mathrm{C}\right)^{a}\end{array}$ & $\begin{array}{l}\text { Viscosity at } \\
40^{\circ} \mathrm{C}(\mathrm{mPa} \cdot \mathrm{s})^{\mathrm{b}}\end{array}$ & $\begin{array}{l}\text { Density at } \\
15^{\circ} \mathrm{C}\left(\mathrm{kg} / \mathrm{m}^{3}\right)^{\mathrm{c}}\end{array}$ \\
\hline \multicolumn{8}{|l|}{ Methyl } \\
\hline Methyl laurate & $\mathrm{C}_{13} \mathrm{H}_{26} \mathrm{O}_{2}$ & 12 & 0 & 214.11 & $4-5$ & 2.08 & 873.28 \\
\hline Methyl myristate & $\mathrm{C}_{15} \mathrm{H}_{30} \mathrm{O}_{2}$ & 14 & 0 & 242.13 & 18 & 2.84 & 868.18 \\
\hline Methyl palmitate & $\mathrm{C}_{17} \mathrm{H}_{34} \mathrm{O}_{2}$ & 16 & 0 & 270.15 & $32-35$ & 3.76 & 864.19 \\
\hline Methyl stearate & $\mathrm{C}_{19} \mathrm{H}_{38} \mathrm{O}_{2}$ & 18 & 0 & 298.17 & $37-41$ & 4.99 & 867.55 \\
\hline \multicolumn{8}{|l|}{ Ethyl } \\
\hline Ethyl caproate & $\mathrm{C}_{8} \mathrm{H}_{16} \mathrm{O}_{2}$ & 6 & 0 & 144.06 & $-67^{\mathrm{d}}$ & - & 878.56 \\
\hline Ethyl caprate & $\mathrm{C}_{12} \mathrm{H}_{24} \mathrm{O}_{2}$ & 10 & 0 & 200.1 & $-20^{\mathrm{d}}$ & 1.60 & 873.34 \\
\hline Ethyl laurate & $\mathrm{C}_{14} \mathrm{H}_{28} \mathrm{O}_{2}$ & 12 & 0 & 228.12 & $-2^{e}$ & 2.22 & 867.96 \\
\hline Ethyl myristate & $\mathrm{C}_{16} \mathrm{H}_{32} \mathrm{O}_{2}$ & 14 & 0 & 256.14 & $11-12^{\mathrm{a}}$ & 2.99 & 867.65 \\
\hline Ethyl palmitate & $\mathrm{C}_{18} \mathrm{H}_{36} \mathrm{O}_{2}$ & 16 & 0 & 284.16 & $24-26^{a}$ & 3.96 & 864.39 \\
\hline Ethyl stearate & $\mathrm{C}_{20} \mathrm{H}_{40} \mathrm{O}_{2}$ & 18 & 0 & 312.18 & $34-38^{\mathrm{a}}$ & 5.03 & 858.72 \\
\hline Ethyl oleate & $\mathrm{C}_{20} \mathrm{H}_{38} \mathrm{O}_{2}$ & 18 & 1 & 310.18 & $-32^{\mathrm{a}}$ & 4.21 & 877.18 \\
\hline Ethyl linoleate & $\mathrm{C}_{20} \mathrm{H}_{36} \mathrm{O}_{2}$ & 18 & 2 & 308.18 & - & - & 883.18 \\
\hline
\end{tabular}


Table 2

Composition of the synthetic ethyl esters.

\begin{tabular}{|c|c|c|c|c|c|c|c|c|}
\hline FAEE, wt\% & Ethyl caproate & Ethyl caprate & Ethyl laurate & Ethyl myristate & Ethyl palmitate & Ethyl stearate & Ethyl oleate & Ethyl linoleate \\
\hline Ethyl caproate & 96.08 & & & & & & & \\
\hline Ethyl caprate & & 97.88 & & & & & & \\
\hline Ethyl laurate & 3.92 & & 92.28 & & & & & \\
\hline Ethyl myristate & & & & 100 & & & 2.07 & \\
\hline Ethyl palmitate & & 2.12 & & & 100 & 2.05 & 5.38 & \\
\hline Ethyl palmitoleate & & & & & & & 6.54 & \\
\hline Ethyl stearate & & & & & & 97.75 & & \\
\hline Ethyl oleate & & & 7.72 & & & & 76.41 & \\
\hline Ethyl linoleate & & & & & & & 8.80 & 100 \\
\hline$n^{a}$ & 8.15 & 12.09 & 14.35 & 16 & 18 & 19.96 & 19.61 & 20 \\
\hline $\mathrm{db}^{\mathrm{b}}$ & 0 & 0 & 0.08 & 0 & 0 & 0 & 1.06 & 2 \\
\hline
\end{tabular}

a Weighted-average number of carbon atoms in the FAEE

${ }^{b}$ Weighted-average number of double bonds in the FAEE.

Table 3

Fatty acid profile of the palm-oil biodiesel fuel.

\begin{tabular}{lc}
\hline FAME, wt\% & Palm \\
\hline Methyl laurate & 0.22 \\
Methyl myristate & 0.83 \\
Methyl palmitate & 42.52 \\
Methyl palmitoleate & 0.13 \\
Methyl stearate & 4.77 \\
Methyl oleate & 41.27 \\
Methyl linoleate & 10.09 \\
Methyl linolenate & 0.16 \\
Ester content & 100 \\
$\mathrm{n}^{\mathrm{a}}$ & 18.05 \\
$\mathrm{db}^{\mathrm{b}}$ & 0.62 \\
\hline
\end{tabular}

a Weighted-average number of carbon atoms in the FAME.

b Weighted-average number of double bonds in the FAME

Every methyl or ethyl ester fuel was tested for a minimum of two humidities (or vapor pressures), using for that the equilibrium of the salts described in Table 5. The salts were purchased in Panreac and are of synthesis grade.

\section{Experimental equipment and procedure}

Lubricity was measured with a HFRR (PCS Instruments, London, U.K.) following the European EN ISO 12156-1:2006 standard and the ASTM D 6079 standard. The volume of the fuel samples was $2 \mathrm{~mL}$ and its temperature was set to $60^{\circ} \mathrm{C}$. A steel ball and a steel disk were completely submerged in the test fuel and put in contact with each other. The steel ball is held with a vibrator arm and loaded with $200 \mathrm{~g}$ mass. Then a vibration of $1 \mathrm{~mm}$ at a frequency of $50 \mathrm{~Hz}$ for $75 \mathrm{~min}$ causes a wear scar on both the ball and the
Table 5

Salts used to reach different vapor pressure in the HFRR chamber.

\begin{tabular}{llll}
\hline Salt & $\begin{array}{l}\text { Temperature } \\
\left({ }^{\circ} \mathrm{C}\right)\end{array}$ & $\begin{array}{l}\text { Relative } \\
\text { humidity }(\%)\end{array}$ & $\begin{array}{l}\text { Vapor } \\
\text { pressure }(\mathrm{kPa})\end{array}$ \\
\hline Sodium hydroxide $(\mathrm{NaOH})$ & $25-28$ & $8-9$ & $0.25-0.35$ \\
Potassium acetate $\left(\mathrm{KCH}_{3} \mathrm{CH}_{2}\right)$ & $25-28$ & $21-22$ & $0.66-0.86$ \\
Magnesium chloride $\left(\mathrm{MgCl}_{2}\right)$ & $25-28$ & $32-33$ & $1.01-1.29$ \\
Potassium carbonate $\left(\mathrm{K}_{2} \mathrm{CO}_{3}\right)$ & $25-28$ & $42-43$ & $1.33-1.68$ \\
Sodium bromide $(\mathrm{NaBr})$ & $25-28$ & $55-56$ & $1.74-2.10$ \\
Potassium chloride $(\mathrm{KCl})$ & $25-28$ & $82-83$ & $2.60-3.20$ \\
\hline
\end{tabular}

disk. The wear scar on the ball, that represents the lubricating efficiency, was estimated by measuring the mean diameter of the scar (MWSD) obtained from the length of the wear scar in the axis parallel and perpendicular to the ball displacement using a stereomicroscope Optika SZR1 equipped with $100 \times$ magnification lens.

All tests were made inside a climatic chamber where the ambi ent temperature and humidity were controlled with the use of salts. The climatic chamber is a specific cabinet produced by PCS instruments. Temperature and relative humidity are controlled and instantaneously displayed on the HFRR board.

Prior to use, the test components were submerged into $10 \mathrm{~min}$ ultrasonic-baths, first two using toluene and a final cleaning bath with acetone. Experiments were repeated twice and repeatability was demonstrated to be less than $20 \mu \mathrm{m}$ [28], which is acceptable according to the European standard which has shown a repeatability of $63 \mu \mathrm{m}$ and to the American standard that has a repeatability of $80 \mu \mathrm{m}$ (slightly higher because of the non-existent correction for the ambient humidity).

Water content in the fuel samples was measured with a Karl Fischer $756 \mathrm{KF}$ Coulometer from Metrohm, following the method described in standard EN-12937.

Table 4

Composition of the biodiesel fuels made of ethyl esters from different sources of oil.

\begin{tabular}{|c|c|c|c|c|c|c|}
\hline FAEE, wt\% & Waste frying oil & Soybean & Sesame & Linseed & Camelina & Rapeseed \\
\hline Ethyl myristate & 0.44 & 0 & 0 & 0.95 & 0 & 0 \\
\hline Ethyl palmitate & 14.17 & 12.81 & 9.54 & 6.9 & 6.9 & 5.04 \\
\hline Ethyl palmitoleate & 2.37 & 0 & 0 & 0 & 0 & 0 \\
\hline Ethyl stearate & 3.93 & 6.52 & 5.88 & 4.46 & 2.88 & 9.22 \\
\hline Ethyl oleate & 66.4 & 29.37 & 40.27 & 21.34 & 17.37 & 59.55 \\
\hline Ethyl linoleate & 10.33 & 46.06 & 43.13 & 17.27 & 33.47 & 17.74 \\
\hline Ethyl linolenate & 0.77 & 4.92 & 0.34 & 49.08 & 26.03 & 6.59 \\
\hline Ethyl arachirate & 0 & 0.32 & 0 & 0 & 1.33 & 0.51 \\
\hline Ethyl gadoleate & 1.59 & 0 & 0.84 & 0 & 12.01 & 1.36 \\
\hline Ester content & 97.68 & 98.72 & 97.58 & 99.27 & 96.79 & 98.78 \\
\hline $\mathrm{n}^{\mathrm{a}}$ & 19.65 & 19.73 & 19.81 & 19.81 & 20.09 & 19.92 \\
\hline $\mathrm{db}^{\mathrm{b}}$ & 0.93 & 1.36 & 1.28 & 2.03 & 1.74 & 1.16 \\
\hline
\end{tabular}

a Weighted-average number of carbon atoms in the FAEE

b Weighted-average number of double bonds in the FAEE. 


\section{Water correction factors}

The standard UNE-EN ISO 12156-1 proposes the following equation to calculate the wear scar of the samples, with a correction depending on the temperature and relative humidity of the air measured through the vapor pressure:

$W S 1.4=M W S D+H C F\left(1.4-\overline{p_{v}}\right)$

where WS1.4 is the wear scar normalized to a vapor pressure of $1.4 \mathrm{kPa}$ and $\overline{p_{v}}$ is the mean vapor pressure during the test time. $H C F$ is, according to the standard, a constant value of $60 \mu \mathrm{m} / \mathrm{kPa}$, but a value depending on the composition of each fuel would predict more accurately the lubricating efficiency. This factor was obtained by differentiating Eq. (1) with respect to the vapor pressure and solving the equation for $\mathrm{HCF}$ :

$H C F=\frac{d M W S D}{d \overline{p_{v}}}$

The hygroscopy of a fuel depends on its composition and accounts for the amount of water which is absorbed from humid air (quantified with its humidity or vapor pressure). In a previous study [20] the effect of humidity on the wear scar was proposed to be an indirect effect of the hygroscopy of the fuel. Therefore, since each fuel has a different hygroscopy, depending on its composition, a constant value of $60 \mu \mathrm{m} / \mathrm{kPa}$ would not be accurate to correct the effect of vapor pressure for all the fuels. The new parameters proposed to measure this effect are derived from the psychrometry theory:

- The water-air correction factor (WACF):

$$
W A C F=\frac{d M W S D}{d Y_{\mathrm{H}_{2} \mathrm{O} / \text { air }}}=H C F \frac{d p_{v}}{d Y_{\mathrm{H}_{2} \mathrm{O} / \text { air }}}
$$

- The water-fuel correction factor (WFCF):

$$
W F C F=\frac{d M W S D}{d Y_{\mathrm{H}_{2} \mathrm{O} / \text { fuel }}}
$$

- The hygroscopy (Hy) of the fuel:

$$
H y=\frac{d Y_{\mathrm{H}_{2} \mathrm{O} / \text { fuel }}}{d Y_{\mathrm{H}_{2} \mathrm{O} / \text { air }}}=\frac{\frac{d M W S D}{W F C F}}{\frac{\text { WMWSD }}{\text { WACF }}}=\frac{\text { WACF }}{W F C F}
$$

where $Y_{\mathrm{H}_{2} \mathrm{O} / \text { air }}$ and $Y_{\mathrm{H}_{2} \mathrm{O} / \text { fuel }}$ are the mass fraction of water vapor in the humid air and the mass fraction of water in the fuel respectively.

\section{Results and discussion}

\subsection{Lubricity of FAMES and FAEEs}

\subsubsection{Humidity correction factor (HCF)}

The change in the non-corrected wear scar through different vapor pressures between 0.25 and $2.75 \mathrm{kPa}$ can be observed in Figs. 1 and 2. The relation between the MWSD and the vapor pressure is approximately linear and Eq. (2) can be applied to calculate the different HCF. The linear equations which best fitted the experimental results with the correction factors for all the methyl and ethyl esters are collected in Tables 6 and 7. The R-squared value of the lines is always higher than 0.9 which proves a good linear correlation between the data. As can be seen in Fig. 2 only a few lubricity tests could be performed at different humidities for the different fuels because not enough quantity was available for these fuels. Therefore the accuracy in the HCF calculation could be affected.

No clear correlation was found between number of carbons and the value of $H C F$ as it can be seen in Fig. 3 but the HCFs of FAMEs

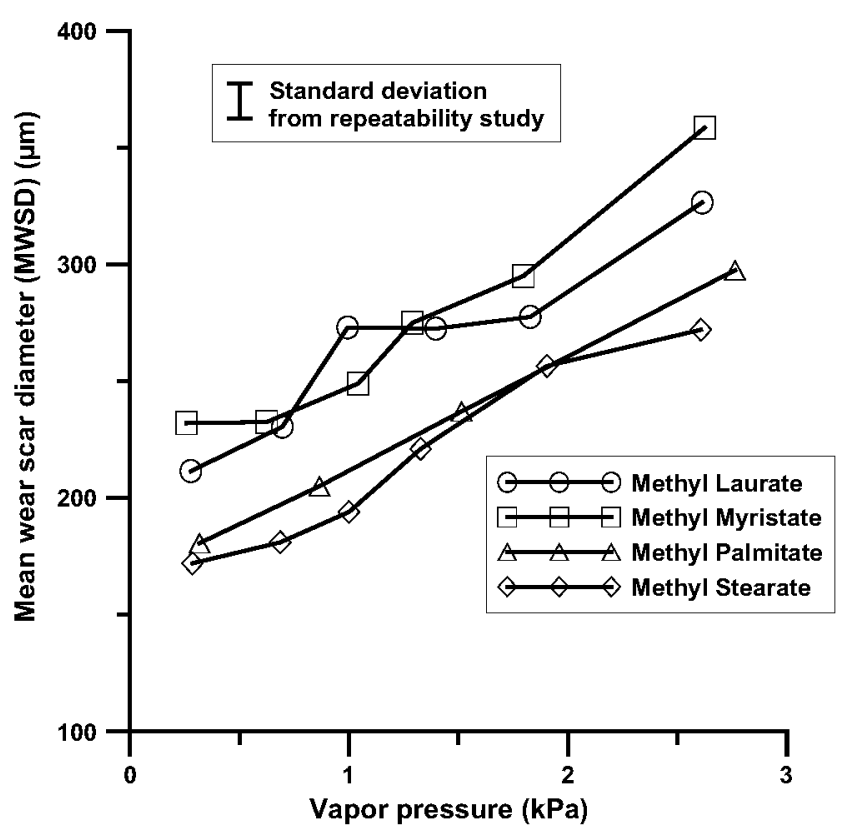

Fig. 1. MWSD of FAMEs.

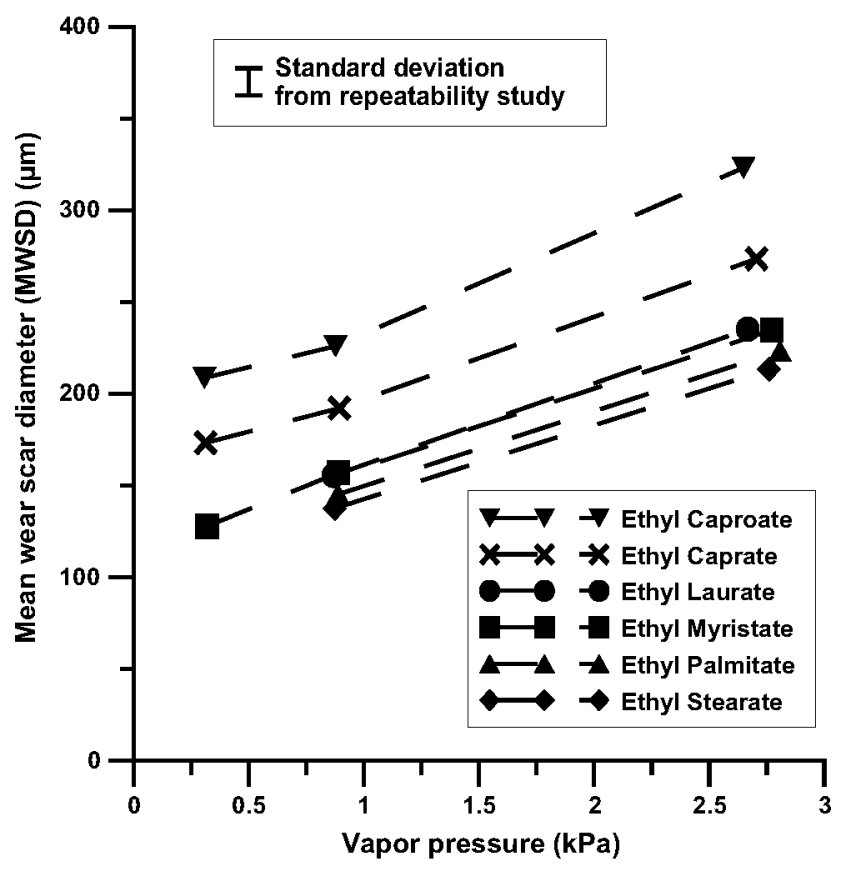

Fig. 2. MWSD of FAEEs.

Table 6

HCFS of FAMEs.

\begin{tabular}{llll}
\hline FAMEs & $M W S D(\mu \mathrm{m})$ linear fit & $H C F(\mu \mathrm{m} / \mathrm{kPa})$ & $\mathrm{R}^{2}$ \\
\hline Methyl laurate & $45.83 p_{v}+205.65$ & 45.83 & 0.9108 \\
Methyl myristate & $55.61 p_{v}+202.94$ & 55.61 & 0.9538 \\
Methyl palmitate & $48.00 p_{v}+164.55$ & 48.00 & 0.9997 \\
Methyl stearate & $47.75 p_{v}+153.95$ & 47.75 & 0.9643 \\
\hline
\end{tabular}

are always higher than those of FAEEs, for the same length of the carbon chain. In the case of FAEEs, generally an increase in the number of carbons of the fatty acid chain leads to a reduction in the HCF. Comparing the values of HCF obtained with the standard 
Table 7

HCFs of FAEEs.

\begin{tabular}{llll}
\hline FAEEs & $M W S D(\mu \mathrm{m})$ linear fit & $H C F(\mu \mathrm{m} / \mathrm{kPa})$ & $\mathrm{R}^{2}$ \\
\hline Ethyl caproate & $50.35 p_{v}+188.20$ & 50.35 & 0.9911 \\
Ethyl caprate & $42.67 p_{v}+157.30$ & 42.67 & 0.9968 \\
Ethyl laurate & $44.33 p_{v}+116.92$ & 44.33 & - \\
Ethyl myristate & $43.01 p_{v}+116.02$ & 43.01 & 0.9982 \\
Ethyl palmitate & $40.72 p_{v}+108.94$ & 40.72 & - \\
Ethyl stearate & $40.22 p_{v}+102.30$ & 40.22 & - \\
\hline
\end{tabular}

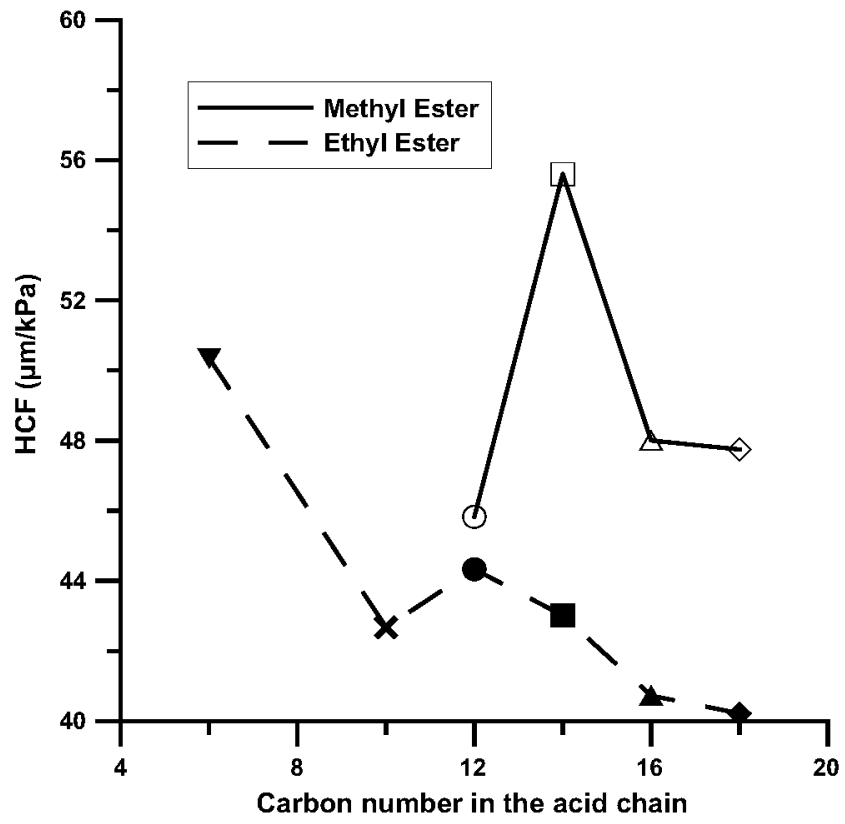

Fig. 3. Variation of HCF with the number of carbons.

value of $60 \mu \mathrm{m} / \mathrm{kPa}$ given by the EN $12156-1$, all of them are below the standard. Therefore the use of HCF set by EN-12156-1 for the calculation of the corrected lubricity (WS1.4) would be wrong, overestimating or underestimating the wear scar produced by the fuels, depending on the vapor pressure when the lubricity test is carried out [20].

\subsubsection{Influence of composition on lubricity}

The lubricity results (WS1.4) for pure FAMEs and synthetic FAEEs are reported in Figs. 4 and 5. To obtain these results the $H C F$ values calculated in the previous section have been used. Fig. 4 shows a clear decreasing trend of the wear scar with the increase of the number of carbons in the fatty acid chain. This effect agrees with previous studies where it is shown that molecules with the same structure and functional group, improve their lubricity with the increase in their molecular weight [3]. Especially in the case of FAEEs, a more sudden decrease of wear scar is observed between the caprylate and laurate ethyl ester while for shorter and longer carbon chain the wear scar seems to stabilize. Also, it can be noticed in Fig. 4 that both methyl and ethyl esters remain below the maximum wear scar value that sets the EN 590 Standard.

Results show that FAEEs have better lubricity than FAMEs, probably because of their different molecular conformation. Short alkyl esters possess polarity in their head-groups that provide an amphipathic nature resulting in a head-to-head alignment of molecules [29]. To the contrary, larger alkyl esters have nonpolar head-groups that are able to neutralize the forces between more polar portions of the head-group aligning themselves in a head-to-tail arrangement with much larger molecular spacing.

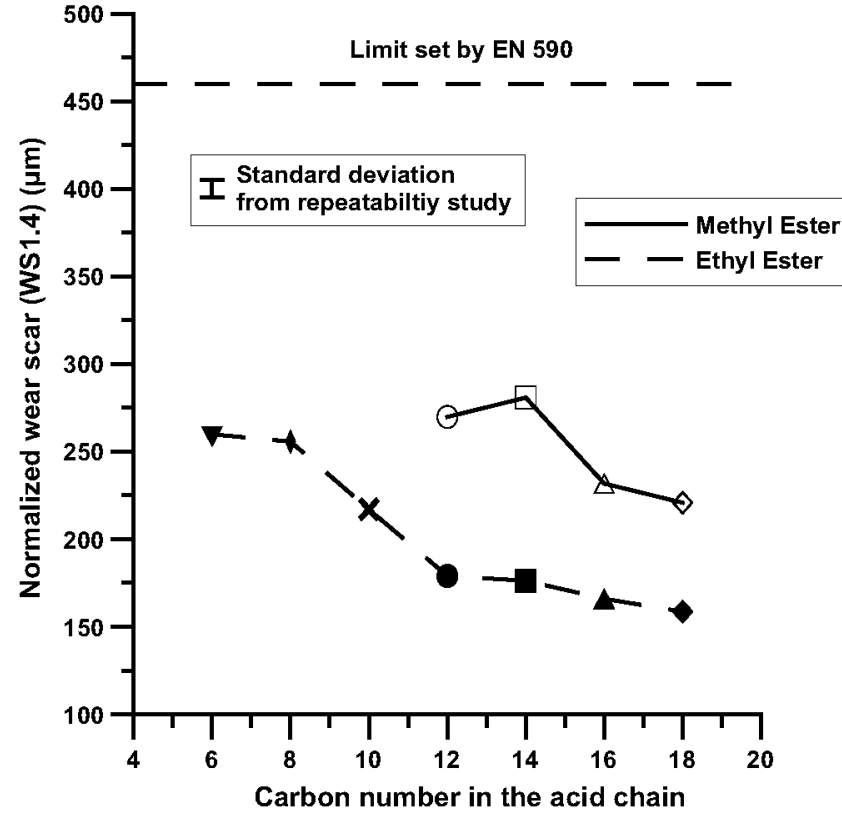

Fig. 4. Normalized wear scar of FAMEs and FAEEs.

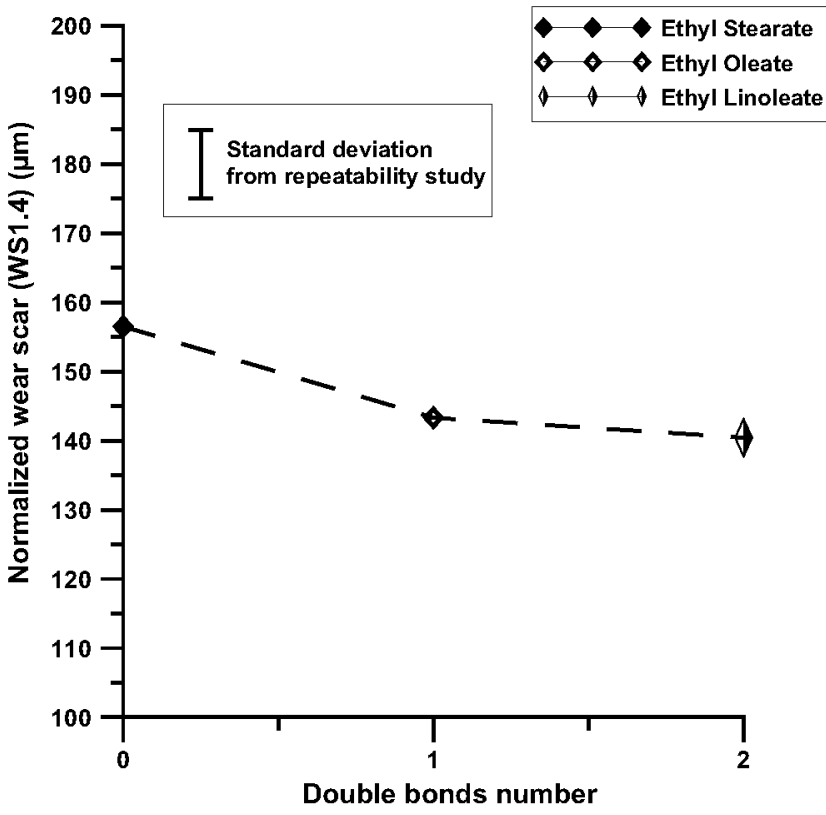

Fig. 5. Effect of the unsaturation of $C_{18}$ FAEEs on the lubricity.

Such voluminous head-groups disrupt the spacing between individual molecules in the crystal structure causing rotational disorder in the hydrocarbon tail-group. In the case of FAEEs, the length of the alcohol chain is still short enough to let the molecules organize in a head-to-head arrangement, producing better lubricity due to the length increase of the complete structure.

Fig. 5 shows that the increase in the unsaturation causes slightly better lubricity, in accordance with previous studies [30]. It is important to indicate that this effect is opposite to the behavior of these compounds concerning their viscosity. The viscosity decreases with the number of double bonds, so between the three compounds depicted in the graphic, ethyl linoleate is the one with better lubricity but worse viscosity, confirming that viscosity and lubricity not always are correlated, especially in low-sulfur fuels [1]. 


\subsection{Lubricity of biodiesel fuels}

\subsubsection{Humidity correction factor (HCF)}

Fig. 6 shows the relationship between MWSD and vapor pressure for different biodiesel fuels from different oils. As can be seen in Fig. 6, only four lubricity tests were carried out at different humidities for the different fuels because not enough quantity was available for these fuels. Therefore the accuracy in the $H C F$ calculation could be affected. An approximately linear relation was found between the vapor pressure and the MWSD (the R-squared of all the estimation lines is near 1). The slope of the lines can be calculated using Eq. (2) to estimate the HCFs of the fuels. The best-fit equations together with the correction factors for the biodiesel fuels are collected in Table 8 . It is important to emphasize that $H C F$ values are very similar for all the fuels tested and oscillate between 38 and $46 \mu \mathrm{m} / \mathrm{kPa}$. This range is similar to that observed for pure methyl and ethyl esters with carbon number higher than 14 (shortest ester composing the biodiesel fuels tested) in Section 5.1.1.

As previously noted for the individual FAMEs or FAEEs, all the fuels have an HCF lower than $60 \mu \mathrm{m} / \mathrm{kPa}$. Therefore, the use of the standard would overestimate or underestimate the wear scar produced, and individual values of $H C F$ for each type of fuel would improve the precision in the estimation of the WS1.4.

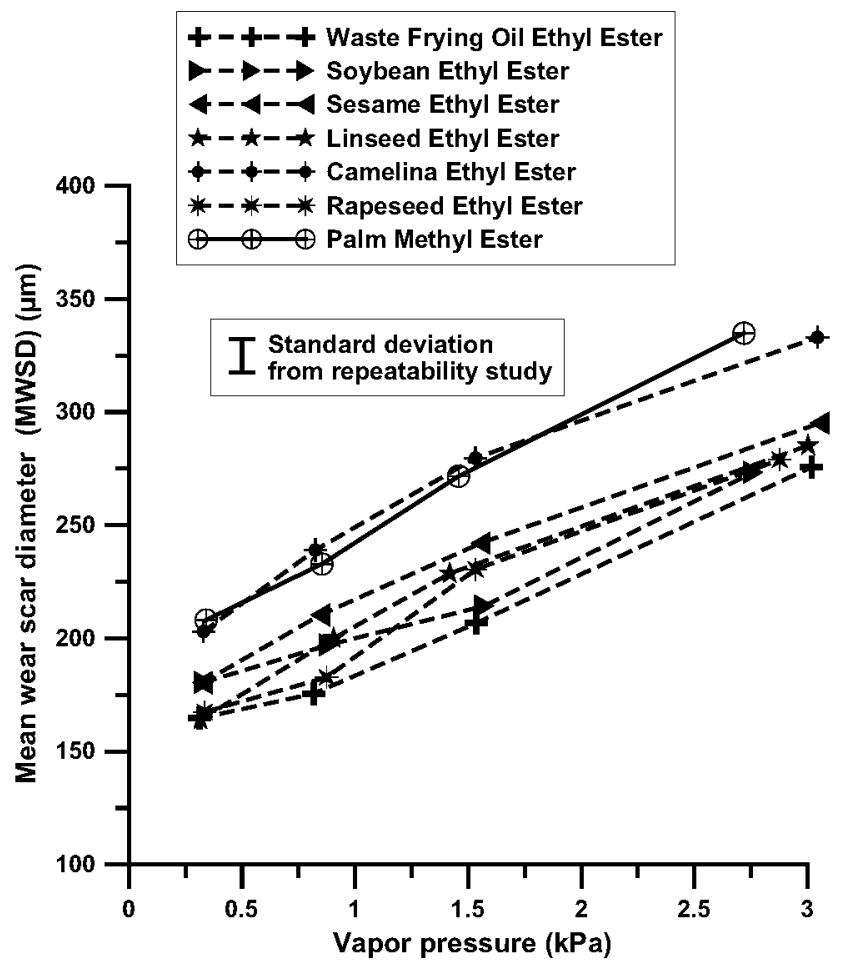

Fig. 6. MWSD of biodiesel fuels.

Table 8

$H C F$ of biodiesel fuels.

\begin{tabular}{lllll}
\hline & Fuel & $\begin{array}{l}\text { MWSD }(\mu \mathrm{m}) \\
\text { linear fit }\end{array}$ & $\begin{array}{l}H C F \\
(\mu \mathrm{m} / \mathrm{kPa})\end{array}$ & $\mathrm{R}^{2}$ \\
\hline \multirow{2}{*}{ FAME } & Palm & $53.87 p_{v}+189.52$ & 53.87 & 0.9976 \\
FAEEs & Waste frying oil & $42.23 p_{v}+145.68$ & 42.23 & 0.9898 \\
& Soybean & $38.16 p_{v}+163.45$ & 38.16 & 0.9749 \\
& Sesame & $41.17 p_{v}+172.48$ & 41.17 & 0.9891 \\
& Linseed & $43.94 p_{v}+157.50$ & 43.94 & 0.9800 \\
& Camelina & $46.58 p_{v}+196.95$ & 46.58 & 0.9721 \\
& Rapeseed & $45.44 p_{v}+151.05$ & 45.44 & 0.9799 \\
\hline
\end{tabular}

\subsubsection{Influence of composition on lubricity}

The lubricity results of biodiesel fuels are reported in Table 9. To obtain these results the HCF values calculated in the previous section have been used. The table shows that all the biodiesel fuels accomplish the American (with normalized wear scars below $520 \mu \mathrm{m}$ ) and European (below $460 \mu \mathrm{m}$ ) standards. As can be observed in Table 4, the biodiesel fuels tested have different average number of carbon atoms and different average number of double bonds. These factors, together with the eventual impurities, are expected to have some influence on the lubricity of the fuels, as reported in other studies $[3,30]$. Normalized wear scars are in general slightly higher than the values previously shown in Figs. 4 and 5 for pure ethyl esters with more than 14 carbon atoms and different degrees of unsaturation. In any case, among the tested biodiesel fuels, the normalized wear scars obtained are very similar and not differing in more than $60 \mu \mathrm{m}$, approximately, which is close to the minimum difference between tests to be considered significant in EN ISO 12156-1.

\subsection{Correlation for WS1.4 and HCF for methyl and ethyl esters}

As commented above, the biodiesel fuels tested have different average number of carbon atoms and different average number of double bonds and these factors are expected to have some influence on the lubricity of the fuels and on the effect of humidity. Therefore, two different correlations have been proposed to calculate the normalized wear scar (WS1.4) and the humidity correction factor $(H C F)$ as a function of the carbon atoms number, the degree of unsaturation (that can be measured by the average number of double bonds) and the type of transesterification. To obtain these correlations all the results presented previously with pure methyl and ethyl esters and biodiesel fuels have been used. The following equations have been obtained to estimate the WS1.4 (Eq. (6)) and the $H C F$ (Eq. (7)) using these three parameters.

$W S 1.4=381.54-8.17 n+49.05 d b-66.79(m-1) \quad R^{2}=0.845$

$H C F=60.65-0.65 n+2.33 d b-7.77(m-1) \quad R^{2}=0.619$

where

$n$ : Average number of carbon atoms.

$d b$ : Average number of double bonds.

$m$ : Number of carbon atoms of the alcohol used for transesterification ( 1 if the transesterification was carried out with methanol and 2 if the transesterification was carried out with ethanol).

As can be observed in Eq. (6), as the average number of carbon atoms $(n)$ increases, the normalized wear scar (WS1.4) decreases. In previous studies, fuels were shown to improve their lubricity as their molecular weight was increased [3]. Therefore, the results obtained with Eq. (6) are in agreement with those previous studies.

Table 9

Nomalized wear scar of biodiesel fuels.

\begin{tabular}{lll}
\hline & Fuel & WS1.4 $(\mu \mathrm{m})$ \\
\hline FAME & Palm & 264.93 \\
FAEE's & Waste frying oil & 204.79 \\
& Soybean & 216.87 \\
& Sesame & 230.12 \\
& Linseed & 219.02 \\
& Camelina & 262.16 \\
& Rapeseed & 214.67 \\
\hline
\end{tabular}


Regarding the type of transesterification, it can be seen in Eq. (6) that transesterification with ethanol, instead of methanol, has an enhanced effect in lubricity. This result is also in agreement with the results obtained in Fig. 4. The correlation for HCF (Eq. (7)) has not such a good R-squared coefficient. The reason for this could be that the number of lubricity tests carried out at different humidities is not enough and this has a negative impact in the accuracy of the estimated HCF. As can be observed in Eq. (7), as the average number of carbon atoms increases and the average number of double bonds decreases, the HCF obtained becomes smaller than the HCF set by EN ISO 12156-1. Therefore the Standard overestimates the HCF. Furthermore, transesterification with ethanol contributes to decrease the humidity correction factor for every biodiesel fuel. The effect of the type of transesterification is more significant in the HCF than the effect of the carbon atoms number and the double bonds number. The results obtained with the two correlations are shown in Figs. 7 and 8.

\subsection{Influence of the water content in the fuel on the lubricity}

In previous sections, the effect of humidity in the ambient air on the fuel lubricity was presented. In this section the effect of fuel water content in the fuel on its lubricity is analysed by addition of water to the fuels tested. Four pure methyl esters and a biodiesel fuel were selected to characterize the effect of the water content on the lubricity of the fuel. They were all tested under potassium

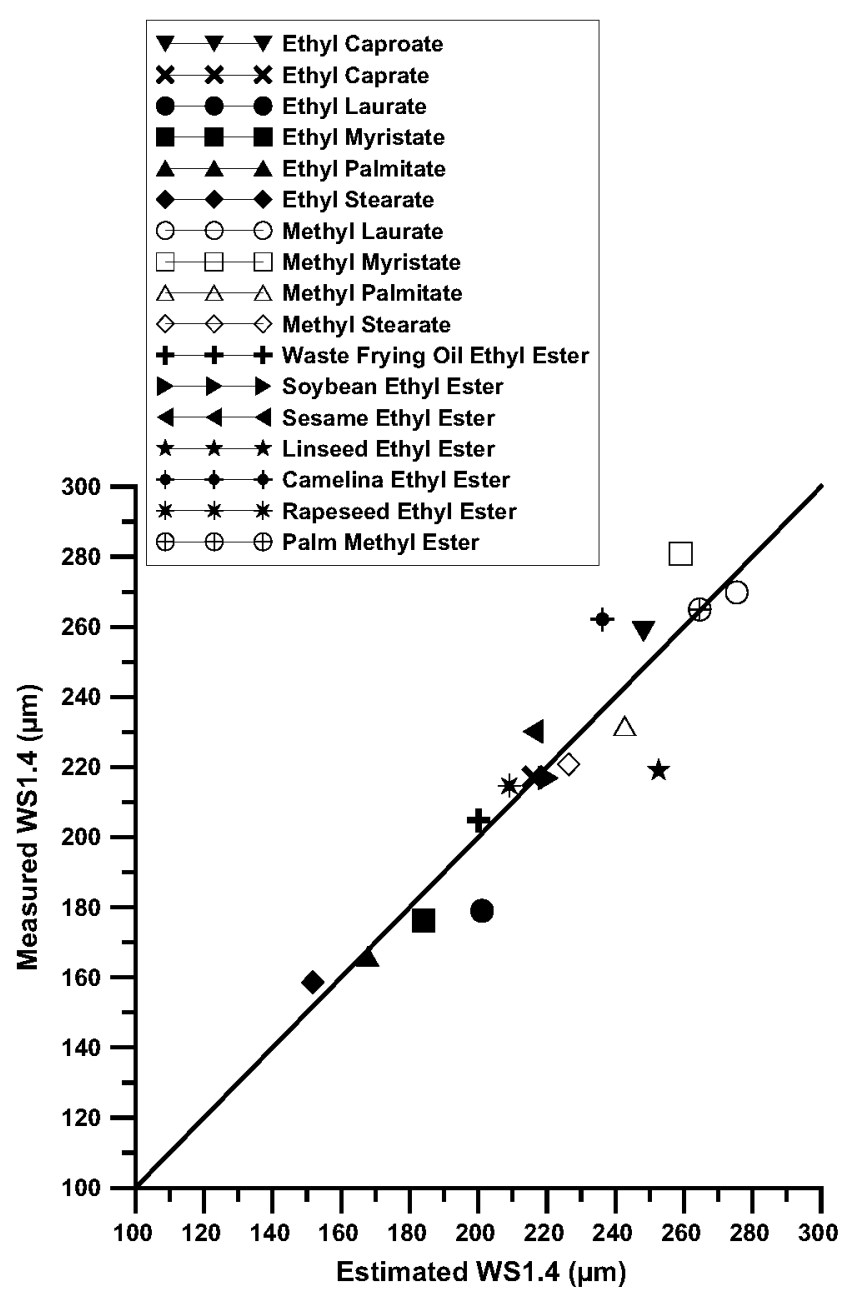

Fig. 7. Correlation for the estimation of WS1.4 and the experimental values

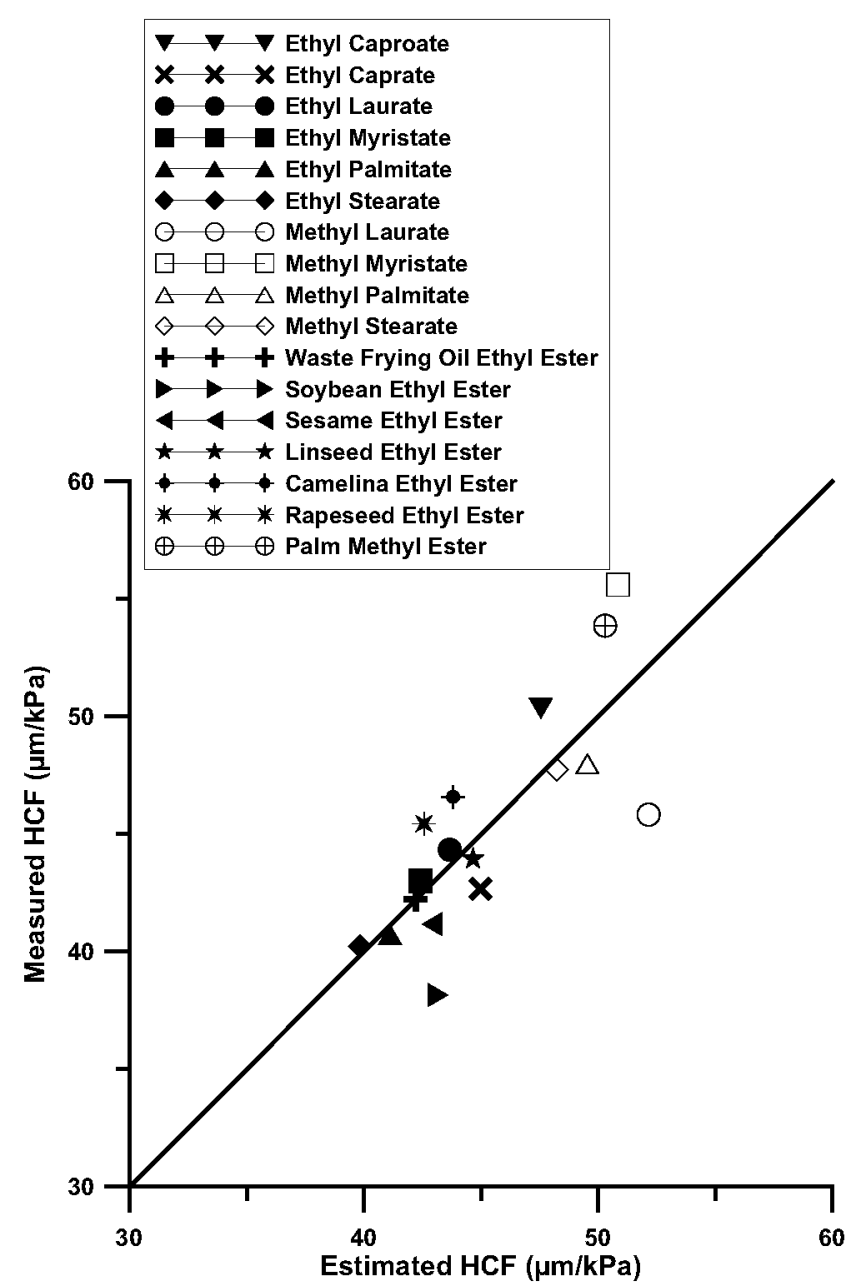

Fig. 8. Correlation for the estimation of $H C F$ and the experimental values.

acetate environment (vapor pressure from 0.66 to $0.86 \mathrm{kPa}$ ) and laboratory ambient pressure of $94.25 \mathrm{kPa}$. Fig. 9 shows that two water additions were made to each fuel, of approximately 100 and $200 \mathrm{ppm}$. In all samples, an increase in water content produces an increase in wear scar. The presence of water prevents the formation of the third body debris layer on the metal surface [31] and thus adhesive wear is not likely to occur to the same extent According to [32], this third body layer is often composed of particles detached from the rubbing surfaces which separate the surfaces in contact, avoiding direct interactions. For this reason water content present in the fuel cause a major abrasion and corrosion.

WACF can be obtained using the developed formula of Eq. (3) [20] and WFCF can be estimated using Eq. (4). Results are reported in Fig. 10. Dots connected with solid lines represent saturated methyl esters, and isolated dot corresponds to the biodiesel fuel tested (with some degree of unsaturation). It can be observed that the tendency is the same for WACF and for WFCF. For the same type of chemical compound (in this case methyl esters), when the WACF increases, the same does the WFCF and vice versa. Therefore, water present in environment or water contained in the fuel affect in the same way to the fuel lubricity. This is consistent with the direct effect of the fuel composition on both the normalized wear scar and the humidity correction factor, as shown in Eq. (7), and it also proves that the water content in the fuels is the main cause of the increase in the wear scar when humidity increases (Fig. 11) [20]. The main implication of this conclusion is that the well-known 


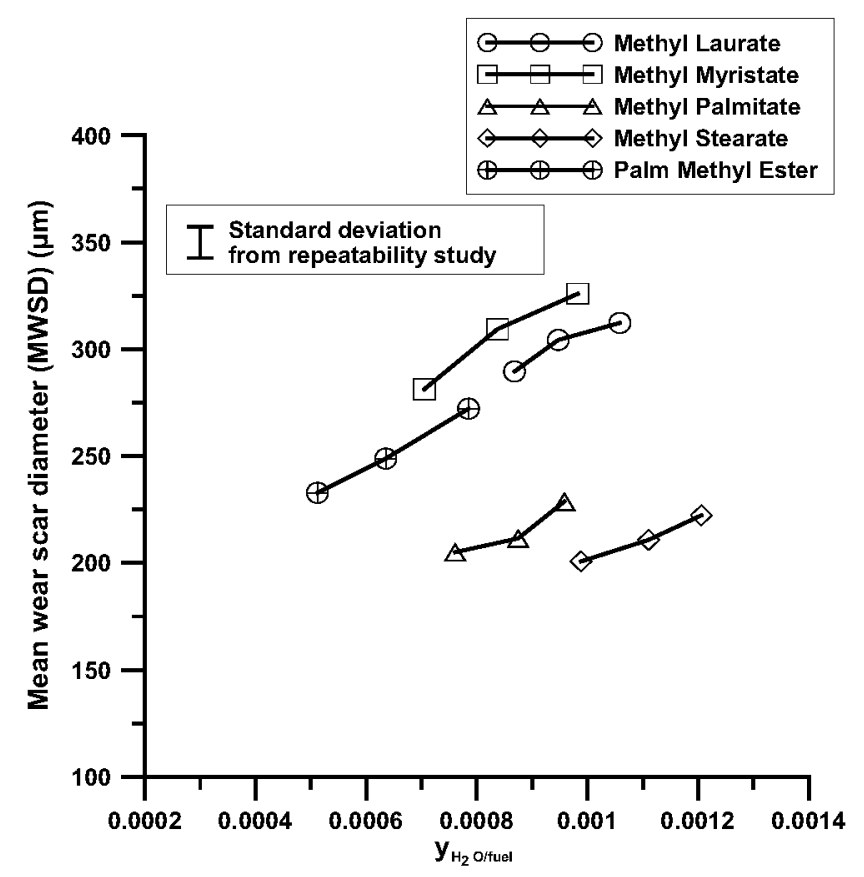

Fig. 9. Influence of water content in the MWSD.

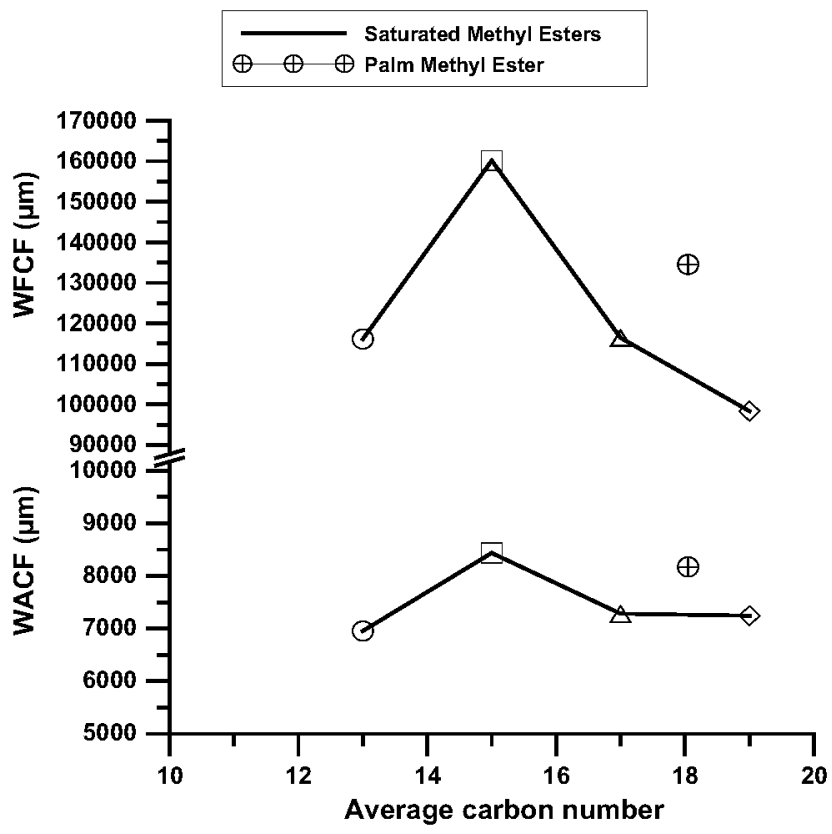

Fig. 10. $W A C F$ and $W F C F$ of pure methyl saturated esters and biodiesel fuel.

benefits in lubricity of biodiesel fuels could be counteracted by their high hygroscopy, which tends to capture water from the ambient air and thus reduce their lubricating properties, as far as they are largely exposed to open atmospheres.

Using the two mentioned parameters, the hygroscopy of each ester can be calculated using Eq. (5) (Fig. 12). In this case, the effect of the carbon number on the hygroscopy is minor, and variations are mainly attributed to inaccuracies in the determination of the effects of water in both: the fuel (WFCF) and the ambient air (WACF). Also, some effect of unsaturation to decrease hygroscopy can be appreciated. However, differences are small and the amount of data is not enough to guarantee the significance of this trend.

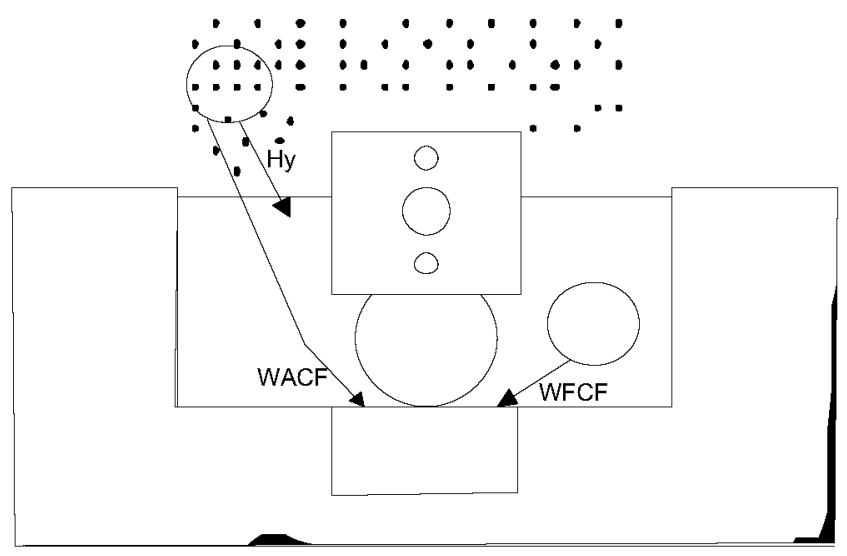

Fig. 11. Effect of water on lubricity.

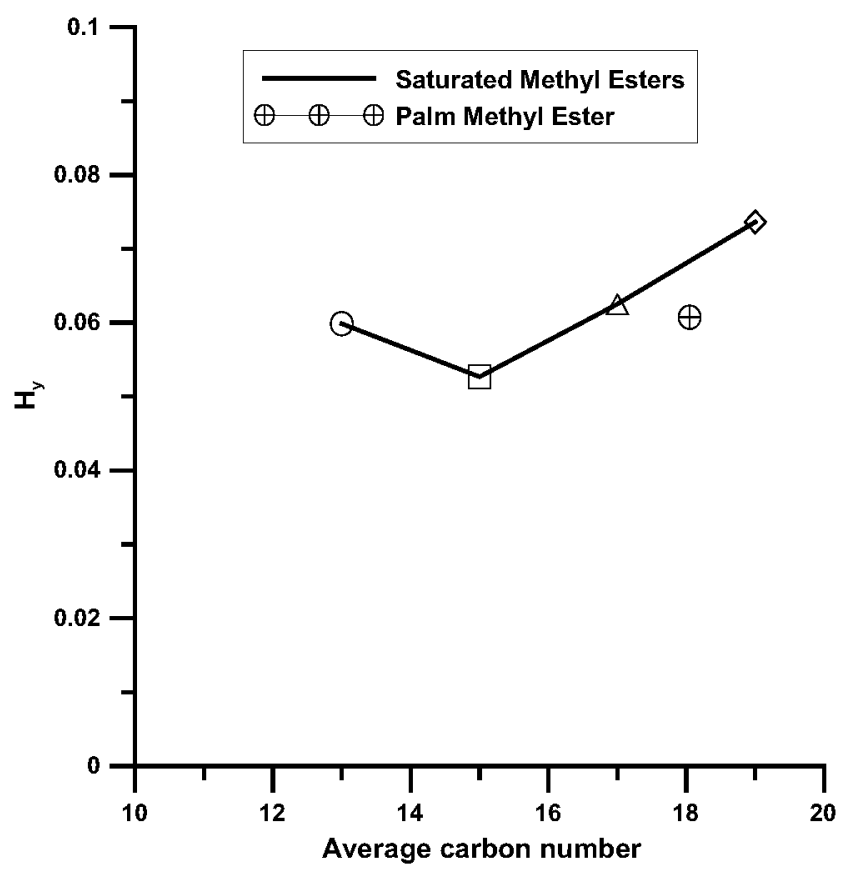

Fig. 12. Hygroscopy of pure saturated methyl esters and biodiesel fuel.

\section{Conclusions}

A high frequency reciprocating rig (HFRR) has been used to study the influence of composition and ambient humidity of the individual components of biodiesel (methyl and ethyl esters) and also of actual biodiesel fuels from different oils on their lubricity. A correlation has been proposed to calculate the normalized wear scar of a biodiesel fuel as a function of the average number of carbons of the acid chain, the average number of double bonds (as a measure of the unsaturation) and the alcohol used for transesterification. The influence of humidity on the lubricity of methyl and ethyl esters and biodiesel fuels has also been studied through the humidity correction factor $(H C F)$. This factor is approximated by the lubricity standard to $60 \mu \mathrm{m} / \mathrm{kPa}$ and all the measurements obtained in this work are below this value. Consequently, the lubricity of biodiesel fuels is underestimated or overestimated (depending on the ambient vapor pressure) when the factor provided by the standard is used. An additional correlation has been proposed to calculate this factor. From both correlations, it can be concluded that when the number of carbon atoms in the acid chain or in the alcohol used for transesterification increase, both 
the normalized wear scar and the humidity correction factor decrease. The effect of the unsaturation on the wear scar is not so clear because it was opposite for pure esters than for biodiesel fuels. These correlations are useful to predict the lubricity of a biodiesel fuel, as well as the effect of humidity on the lubricity, from its fatty acid profile, with good accuracy, as far as the content of impurities in the biodiesel is small enough. Finally, it has been proved that the change in lubricity at different humidities $(H C F)$ is derived from the different chemical composition of the fuel, and also that it is the water content in the fuel what mainly leads to an increase in the wear scar. This implies that the benefits in lubricity of biodiesel fuels could be counteracted by their high hygroscopy when they are exposed to open air for long time.

\section{Acknowledgments}

We thank the Spanish Ministry of Economy and Competitiveness for financial support through project WOLF (Grant ENE2013-48602-C3-1-R), Junta de Comunidades de Castilla-La Mancha - JCCM for a research grant to J.S.-V., "la Caixa" Foundation for a research grant to D.B. and Emilio García for his technical help.

\section{References}

[1] Barbour RH, Rickeard DJ, Elliott NG. Understanding diesel lubricity. SAE technical paper no. 2000-01-1918; 2000.

[2] Mozdzen EC, Wall SW, Byfleet WD. The no-harm performance of lubricity additives for low sulphur diesel fuels. SAE technical paper no. 982571; 1998.

[3] Knothe G, Steidley KR. Lubricity of components of biodiesel and petrodiesel. The origin of biodiesel lubricity. Energy Fuels 2005;19(3):1192-200.

[4] Candeia RA, Freitas JCO, Souza MAF, Conceição MM, Santos IM, Soledade LEB, et al. Thermal and rheological behavior of diesel and methanol biodiesel blends. J Therm Anal Calorim 2007;87(3):653-6.

[5] Benjumea P, Agudelo J, Agudelo A. Basic properties of palm oil biodiesel-diesel blends. Fuel 2008;87(10):2069-75.

[6] Candeia RA, Silva MCD, Carvalho Filho JR, Brasilino MGA, Bicudo TC, Santos IMG, et al. Influence of soybean biodiesel content on basic properties of biodiesel-diesel blends. Fuel 2009;88(4):738-43.

[7] Dwivedi G, Sharma MP. Impact of cold flow properties of biodiesel on engine performance. Renew Sustain Energy Rev 2014;31:650-6.

[8] Zhou W, Konar SK, Boocock DG. Ethyl esters from the single-phase basecatalyzed ethanolysis of vegetable oils. J Am Oil Chem Soc 2003:80(4):367-71.

[9] Farrell AE, Plevin RJ, Turner BT, Jones AD, O'Hare M, Kammen DM. Ethanol can contribute to energy and environmental goals. Science $2006 ; 311(5760): 506-8$.
10] Karonis D, Anastopoulos G, Lois E, Stournas S, Zannikos F, Serdari A Assessment of the lubricity of Greek road diesel and the effect of the addition of specific types of biodiesel. SAE technical paper no. 1999-01-1471; 1999.

[11] Knothe G. The lubricity of biodiesel. SAE technical paper no. 2005-01-3672; 2005.

[12] Lacey PI, Howell SA. Fuel lubricity reviewed. SAE technical paper no. 982567 1998.

[13] Hornby B, Cuckston G, Caprotti R, More I. Pushing the boundaries of the HFRR impact of increased test severity on wear. SAE technical paper no. 2013-01$2688 ; 2013$.

[14] EN ISO 12156-1. Diesel fuel: assessment of lubricity using the high frequency reciprocating rig (HFRR)-Part 1: test method. Brussels, Belgium: European Committee for Standardization; 2008.

15] ASTM D 6079. Standard test method for evaluating lubricity of diesel fuels by the High-Frequency Reciprocating Rig (HFRR). West Conshohocken, United States: ASTM International.

[16] ASTM D 975. Standard specification for diesel fuel oils. West Conshohocken, United States: ASTM International.

[17] EN-590. Automotive fuels-diesel requirements and test methods. Brussels, Belgium: European Committee for Standardization; 2009.

[18] World Wide Fuel Charter. 5th ed.; 2013. <www.acea.be>

[19] Lacey PI. Wear with low-lubricity fuels I. Development of a wear mapping technique. Wear 1993;160(2):325-32.

[20] Lapuerta M, Sánchez-Valdepeñas J, Sukjit E. Effect of ambient humidity and hygroscopy on the lubricity of diesel fuels. Wear 2014;309(1):200-7.

[21] Kemp W. Practical organic chemistry. London: McGraw-Hill; 1967. p. 65-7.

[22] Bolonio D, Llamas A, Rodríguez-Fernández J, Al-Lal AM, Canoira L, Lapuerta M et al. Estimation of cold flow performance and oxidation stability of fatty acid ethyl esters from lipids obtained from Escherichia coli. Energy Fuels 2015;29 (4):2493-502.

[23] Sigma Aldrich Corporation.

[24] Pratas MJ, Freitas S, Oliveira MB, Monteiro SC, Lima AS, Coutinho JA. Densities and viscosities of fatty acid methyl and ethyl esters. J Chem Eng Data 2010;55 (9):3983-90.

[25] Lapuerta M, Rodríguez-Fernández J, Armas O. Correlation for the estimation of the density of fatty acid esters fuels and its implications. A proposed biodiesel cetane index. Chem Phys Lipids 2010;163(7):720-7.

[26] www.chemicalbook.com.

[27] www.chemicalspider.com.

[28] Lapuerta M, García-Contreras R, Agudelo JR. Lubricity of ethanol-biodieseldiesel fuel blends. Energy Fuels 2010;24:1374-9.

[29] Sarin A. Biodiesel: production and properties. Royal Society of Chemistry 2012.

[30] Geller DP, Goodrum JW. Effects of specific fatty acid methyl esters on diese fuel lubricity. Fuel 2004;83(17):2351-6.

[31] Lancaster JK. A review of the influence of environmental humidity and water on friction, lubrication and wear. Tribol Int 1990;23:371-89.

[32] Fillot N, Iordanoff I, Berthier Y. Wear modelling and the third body concept. Wear 2007;262:949-57. 